\title{
Conflictos y cambios familiares: significados asociados al consumo de sustancias psicoactivas
}

\author{
Albeiro Callejas-Callejas, Mg. \\ Corporación Universitaria Minuto de Dios. Colombia* \\ María Hilda Sánchez-Jiménez, Ph.D. \\ Universidad de Caldas, Colombia**
}

acallejasca@uniminuto.edu.co

\section{Resumen (analítico)}

Se presentan los contextos sociofamiliares co-construidos, así como los significados dados al conflicto y a los cambios familiares asociados al consumo de sustancias psicoactivas por parte de un hijo adolescente. Es resultado de una investigación cualitativa-hermenéutica, apoyada en el método de la teoría fundamentada y su interpretación tiene como base epistemológica elementos del construccionismo social. Los resultados muestran movimientos, relaciones y estrategias que marcan: pautas de interacción que conjugan problemas y cambios sociofamiliares, alteraciones emocionales y predominancia de relaciones violentas. Concluye que la agudización del conflicto se da en el marco de relaciones fracturadas de acuerdo con el significado centrado en el rol de padre y madre, patrones relacionales violentos y emociones confusas y contradictorias en las relaciones familiares.

\section{Palabras clave}

Drogadicción, relación padres-hijos, adolescente, vida familiar y conflicto.

\section{Thesauro}

Tesauro de Ciencias Sociales de la Unesco.

\section{Para citar este artículo}

Callejas-Callejas, A., \& Sánchez-Jiménez, M. H. (2020). Conflictos y cambios familiares: significados asociados al consumo de sustancias psicoactivas. Revista Latinoamericana de Ciencias Sociales, Niñez y Juventud, 18(2), 1-22. http://dx.doi.org/ $10.11600 / 1692715 \times .18212$

\section{Historial}

Recibido: 08.04.2019

Aceptado: 28.06 .2019

Publicado: 20.05.2020

\section{Información artículo}

El artículo presenta resultados del proyecto «Significados de los conflictos familiares y cambios asociados al consumo de sustancias psicoactivas», código G6H0232. Universidad de Caldas, Colombia. El estudio no contó con financiación institucional. Fecha de inicio: 27 de enero de 2017. Fecha de culminación: 30 de noviembre de 2018. Área: ciencias sociales. Subárea: Estudios de Familia. 


\section{Conflicts and family changes: \\ meanings associated with the consumption of psychoactive substances}

Abstract (analytical)

The paper presents co-constructed socio-family contexts, the meanings given to conflict and the family changes associated with the consumption of psychoactive substances by a teenage child. The authors describe the results of a qualitative-hermeneutic investigation supported by the grounded theory method and its interpretation is based on epistemological elements of social constructionism. The results show movements, relationships and strategies related to: patterns of interaction that combine social and family problems and changes; emotional alterations; and the predominance of violent relationships. The authors conclude that the worsening of conflict occurs within the framework of fractured relationships that depend on the meaning related to the roles of parents, violent relational patterns and confused and contradictory emotions in family relationships.

Keywords

Drug addiction, parent-child relationship, adolescent, family life and conflict.

\section{Conflitos e mudanças familiares: \\ significados associados ao consumo de substâncias psicoativas}

Resumo (analítico)

O artigo apresenta os contextos sócio-familiares co-construídos, os significados atribuídos ao conflito e as mudanças familiares associadas ao consumo de substâncias psicoativas por um filho adolescente. É o resultado de uma investigação qualitativa-hermenêutica, apoiada pelo método da teoria fundamentada e com interpretação baseada em elementos epistemológicos do construcionismo social. Os resultados assim como sua análise mostram movimentos, relações e estratégias que marcam: padrões de interação que combinam problemas e mudanças sociais e familiares, alterações emocionais, e predominância de relações violentas. Conclui-se que o agravamento do conflito ocorre no quadro das relações fraturadas segundo o sentido centrado no papel do pai e da mãe, nos padrões relacionais violentos e nas emoções confusas e contraditórias nas relações familiares.

\section{Palavras-chave}

Dependência química, relação pai-filho, adolescente, vida familiar e conflito.

Información autores

[*] Psicólogo de la Universidad Antonio Nariño. Magíster en Intervención en Relaciones Familiares de la Universidad de Caldas. Profesor Corporación Universitaria Minuto de Dios. Chinchiná, Colombia. Correo electrónico: acallejasca@uniminuto.edu.co iD 0000-0001-8984-0839.

[**] Directora del Trabajo de Grado. Doctora en Psicología de la Universidad de Buenos Aires. Magíster en Psicología Clínica y de Familia de la Universidad Santo Tomás de Aquino. Psicóloga de la Universidad de Manizales. Profesora titular del Departamento de Estudios de Familia. Integrante del grupo de Investigación Colectivo estudios de Familia (Categoría A), Universidad de Caldas. Manizales, Colombia. Correo electrónico: maria.sanchez_j@ucaldas.edu.co iD 0000-0002-4902-7234. 


\section{Introducción}

ـ as familias y los adolescentes, ${ }^{1}$ en el contexto del consumo de sustancias psicoa) la búsqueda de causas y sujetos a quien culpabilizar y juzgar; b) la lucha por encontrar salidas a un estado corporal, emocional y relacional marcado por dolores, rabias y frustraciones; c) la impotencia frente a una sustancia psicoactiva que envuelve a las personas y fragmenta los límites personales e interpersonales; d) el apoyo de redes sociales, institucionales y profesionales especializados donde está viva la esperanza de una cura, pero también el rechazo a los tratamientos. Este círculo vicioso genera contradicciones y confrontaciones del consumidor con su familia y de estos con las instituciones y los profesionales; mientras que, como plantea Ávila-Navarrete (2017), «la efectividad del acto de reeducar depende potencialmente de dos entidades: la institución y la familia» (p. 1193). En medio de este círculo, la atención de los diversos grupos sociales implicados en esta problemática (sea porque la viven en sus relaciones o porque son parte de la prevención, atención y tratamiento) se centran más en sus causas y en la familia como mayor responsable.

La familia cae en la trama de prolongar el señalamiento social, institucional y profesional, entrando en la búsqueda de personas culpables dentro y fuera del grupo, mientras el consumo se agudiza y emergen sentimientos de frustración, rabia, dolor e impotencia. Los procesos terapéuticos son vistos como una alternativa, aunque predomine la mirada hacia el consumidor, en quien debe estar centrado el tratamiento.

En el campo de la psicoterapia - y en todo proceso de intervención- es difícil que las familias o sus integrantes, siendo participes del proceso de adicción, se incluyan como parte del tratamiento. «El consumo de drogas por parte de los miembros más jóvenes puede ser percibido como un estresor que exige cambios en el sistema de funcionamiento familiar» (Martínez, 2015, p. 87). No obstante, «las familias reconocen con extrema superfici-

${ }^{1}$ En este texto se hace referencia a los adolescentes, por cuanto la población que participó fueron familias con hijos hombres. No hubo participación de familias con hijas mujeres. 
alidad los alcances problemáticos de las drogas. Aunque los miembros de la familia expresen gran preocupación, el conjunto de sus declaraciones no manifiesta una crisis ni revela un movimiento activo sobre el cambio» (Stanton \& Tudd, 2018, p. 240). Esto invita a implementar abordajes terapéuticos e investigativos más allá del individuo y a reconocer a la familia como un contexto que mantiene el consumo, pero también como un contexto responsable de su solución. Cuando la familia se involucra existen mayores probabilidades de recuperación y rehabilitación (Domínguez \& Figueroa, 2019).

En la revisión de artículos científicos y tesis de maestría, basados en investigaciones que mencionan a la familia (tal como puede verse más adelante), estos señalan que alteraciones en las relaciones, especialmente de pareja, padres-madres e hijos, separaciones, distanciamientos, falta de autoridad, límites y claridad en los roles están entre las causas principales que conllevan al consumo de sustancias psicoactivas en sus hijos adolescentes. Si bien estos resultados de investigaciones aparecen con frecuencia como causas del consumo, no necesariamente son criterios generalizables.

Por tanto, el presente artículo parte de la pregunta: ¿qué significados y contextos relacionales construyen padres, madres y adolescentes ante el consumo de sustancias psicoactivas? Una de las razones para abordar el contexto familiar es hacer evidente algunos patrones relacionales conflictivos y cambios $^{2}$ en estas familias y, sobre la base de un estudio cualitativo y con enfoque hermenéutico, responder al objetivo de comprender los significados familiares - pautas de relación- en torno a los conflictos y los cambios asociados al consumo de sustancias psicoactivas.

El documento retoma tres aspectos centrales que fueron construidos a partir de las voces de los informantes de cuatro familias, puestos en conversación desde el enfoque construccionista social. Primero, las pautas de interacción familiar que sirven de base en la creación de contextos y significados sobre los conflictos familiares y, por ende, los cambios que van emergiendo a medida que avanza el problema y se transforman las relaciones. Segundo, la alteración de las emociones y expresiones de la agudización del conflicto, lo cual favorece el desequilibrio emocional del grupo familiar; ello se manifiesta mediante sentimientos de frustración, miedo, ansiedad, unidos a la predominancia de relaciones agresivas y violentas. Y, tercero, los significados del rol del padre y rol de la madre en medio de la dinámica del conflicto familiar.

2 El concepto de cambio tiene que ver con los movimientos que se dan en las relaciones intra y extrafamiliares, a través de los cuales se construyen pautas de interacción que profundizan los problemas, generan otros conflictos o pautas que ayudan a encontrar soluciones. 


\section{Reflexiones construccionistas en torno al significado}

\section{y las relaciones ${ }^{3}$}

La construcción del significado es el procedimiento por el cual se le da sentido a un elemento y esto lo logra el individuo por medio de la relación que establece con las cosas ya conocidas o con otras experiencias situacionales. La interacción implica un proceso de conocimiento de lo otro, de su contexto, de su lenguaje. «A través de la coordinación relacional, nace el lenguaje, y a través del lenguaje adquirimos la capacidad de hacernos inteligibles» (Gergen, 2007, p. 222). Hay tres aspectos centrales en la interacción que son resaltados aquí: la acción, el significado y el sentido, lo cual nos permite comprender las experiencias sociales y familiares donde habita cada persona. Esta última «expresa y describe los acontecimientos con sus propias secuencias lógicas, las cuales conservan la sutileza de la relación entre el "decir" (acción), lo "dicho" (significado) y lo que "está por decirse y hacerse" (sentido)» (Sánchez-Jiménez, 2014, p. 194). En otras palabras, las expresiones sobre lo que ha acontecido o acontece es la manera como cada quien percibe su mundo y su experiencia, la cual no escapa del proceso interaccional y social desde el que ha construido esas expresiones y el lenguaje que las habita.

En medio de estas coordinaciones y secuencias lógicas dadas en las interacciones sociales, cada sujeto trasciende su individualidad y la del otro. En ellas se instauran nuevos conocimientos y se modifican aprendizajes adquiridos. Como parte fundamental de la construcción del significado, el desarrollo del lenguaje en una cultura determinada desempeña un papel relevante. Los símbolos son elementos importantes para comprender un significado y sentido en sí mismos; son los que permiten enriquecer el lenguaje propiamente dicho, que su contenido se haga real y manifiesto. En este caso, el sentido y significado se vienen a revelar únicamente cuando el individuo interactúa con el símbolo, el cual ha sido considerado el vehículo de la hermenéutica que, en la interacción, permite la comprensión de estos conceptos. Dado que las emociones están canalizadas en el cuerpo, ellas son expresiones simbólicas articuladas a las palabras y formas de lenguaje que permiten traducir estados de ánimo, acciones, interacciones y, por ende, significados. Como dice Wittgenstein (1953/2008), el cuerpo proporciona las coordenadas que describen un estado de ánimo y permite responder a la pregunta de qué se dice en ese momento que algo se expresa en relación con. El cuerpo también es símbolo y lenguaje.

\footnotetext{
${ }^{3}$ Es importante aclarar que los conceptos de significado, sentido y símbolo se hacen a la luz de planteamientos construccionistas sociales y la hermenéutica. Por lo tanto, aquí en este aparte fue necesario retomar algunos autores clásicos.
} 
En esta relación «el símbolo se refiere al lenguaje que oculta el sentido y al mismo tiempo lo quiere manifestar» (Ricoeur como es citado por Valverde, 2003, p. 5).

Por otro lado, según Arcila et al. (2010), «el lenguaje permite a los sujetos participar en la cultura, entender y construir sus significados. El ejemplo más claro es el caso de los niños recién nacidos que, en la medida que adquieren la capacidad de utilizar el lenguaje, tendrán la capacidad de entender los significados» (p. 7).

Entre los planteamientos del construccionismo, los significados se transforman de manera circular y temporal a medida que las personas interactúan, se complementan o se suplementan mediante significados contextuados que pueden llevar a crear o a restringir (Gergen, 2007). Cuando las interacciones se ven amenazadas o retadas ocurren conflictos y cambia así el proceso de construcción de significados y sentidos. De ahí que la construcción del significado y su transformación responden a las acciones coordinadas entre las personas, tienen la influencia de las relaciones de su comunidad discursiva y, así como se construyen, pueden ser de-construidos. Cualquiera sea el proceso, se requiere un contexto que facilite estos movimientos sociolingüísticos (Gergen, 1996, 2007).

Lo anterior permite comprender cómo los significados evolucionan o se transforman a lo largo del tiempo, están conectados con las acciones, los lenguajes y sus diversos contextos según algo sea realizado en un momento u otro, con uno u otro sujeto, en torno a una premisas o tema y bajo plataformas relacionales específicas, no generalizables. Con este propósito, es necesario tener en cuenta el lenguaje, el sentido, las acciones y los contextos no solo para construir, de-construir y transformar significados, sino también para comprenderlos y explicarlos de la manera más coherente y cercana a las realidades en los que ellos son creados. Al identificar los significados y sus contextos es posible hacer evidente características interaccionales que configuran plataformas y patrones de relación entre las personas y grupos que pertenecen a una comunidad. En nuestro caso, a las familias que tienen una situación común: el consumo de sustancias psicoactivas por parte de un hijo o hija en edad adolescente.

De tal manera, una de las particularidades del presente estudio es precisamente comprender el significado construido por parte de adolescentes que consumieron sustancias psicoactivas, así como de sus padres y madres, quienes narran los conflictos familiares asociados a esta problemática, lo que permite el acercamiento y la comprensión tanto del conflicto y las interacciones familiares como del contexto donde se construyeron los significados. 


\section{Método}

El análisis está respaldado en una investigación cualitativa, caracterizada por: «a) el interés por el significado y la interpretación, b) el énfasis sobre la importancia del contexto y de las personas, y c) la estrategia inductiva hermenéutica» (Maxwell, como es citado en Vasilachis, 2006, p. 26). De ahí el énfasis en la comprensión de los significados de los conflictos familiares y de los cambios asociados al consumo de sustancias psicoactivas construido en las relaciones familiares.

El registro de información se tomó en el segundo período del año 2017 y partió de las voces de padres, madres y adolescentes que estuvieron en tratamiento por consumo de sustancias psicoactivas. ${ }^{4}$ De las 10 familias cuyos adolescentes hombres entre 16 y 18 años habían egresado de la comunidad terapéutica Semillas de amor, por avances en su proceso de recuperación y por cumplimiento de la medida de restablecimiento de derechos, según la Defensoría de Familia (Instituto Colombiano de Bienestar Familiar), solo cuatro familias aceptaron voluntariamente participar como informantes. Los adolescentes de este estudio ya no hacían parte de la institución y por ello se acudió a la autorización de las familias y de ellos para realizar las entrevistas.

Las razones para la no participación se centraron en considerar el consumo como parte de su vida privada y por el temor a reactivar algún problema familiar producto del tipo de preguntas de la guía de entrevista. Las familias que participaron eran de estrato dos, de la ciudad de Manizales. Las entrevistas fueron grabadas previa concertación de tiempos y espacios para el desarrollo de los encuentros, la realización del consentimiento firmado por los informantes y el compromiso de mantener oculta su identidad en cualquier tipo de documento. ${ }^{5}$ Las grabaciones fueron de uso exclusivo del investigador y reposan bajo su tutela. En este sentido, la investigación de la que se derivó este artículo, se rigió bajo los criterios éticos de la American Psychological Association (2010), capítulo de investigación y publicación (especialmente los numerales 8.02, 8.03, 8.05 y, 8.07).

El método hermenéutico fue el vehículo y vínculo del que se dispuso para lograr un proceso de comprensión y acercamiento directo con los padres, madres y adolescentes desde su propio sentir y pensar. Teniendo presente el número de familias que aceptaron

${ }^{4}$ El psicólogo Albeiro Callejas-Callejas, coautor del presente artículo, era el coordinador de la modalidad responsabilidad penal para adolescentes en la comunidad terapéutica Semillas de amor.

5 Siguiendo así los criterios del comité de ética de facultad de la Universidad de Caldas. 
ser informantes (cuatro), se llevaron a cabo entrevistas a profundidad bajo los criterios de la teoría fundamentada (Strauss \& Corbin, 2002), y se realizó la recolección, codificación (abierta, axial y selectiva; véase tabla 1) y el análisis de datos. Tanto el registro como el procesamiento de la información fueron manejados en el software para análisis de datos cualitativos Atlas.ti $7^{\mathrm{TM}}$ (Muñoz \& Sahagún, 2017).

Tabla 1

Ejemplo de codificación abierta, axial y selectiva

\begin{tabular}{|c|c|c|}
\hline Codificación abierta & Codificación axial & Codificación selectiva \\
\hline $\begin{array}{l}\text { Ideas centrales (propiedades y } \\
\text { dimensiones de las relaciones } \\
\text { padres-madres-adolescente) }\end{array}$ & Subcategoría & $\begin{array}{l}\text { Categoría y conceptos para } \\
\text { contraste teórico }\end{array}$ \\
\hline
\end{tabular}

Nos enfrentamos y si uno ha consumido y va a enfrentar ese conflicto no va a ver soluciones, porque obviamente uno está bajo efectos del consumo

Todo era discusiones y alegatos entonces, tal vez, por eso uno evade las situaciones, se retira, por eso yo no permanecía en mi casa. Que pereza uno llegar a lo mismo.

Uno cree que está haciendo bien y empieza a encerrarlo, a gritarlo, a maltratarlos físicamente a golpes, eso en vez de ayudarlos a ellos los hace tirar más para calle.

Nosotros no éramos una familia en la que se escuchara un hijueputazo... Desde ahí se empezaron a ver los golpes, los disgustos, el hurto en nosotros mismos. Yo irrespetaba los espacios de mi mamá y me le llevaba las cosas.
Interacción entre perso-

nas, la circunstancia y

condición de cada perso-

na, familia como contexto

propicio.

Contexto relacional de confrontación, no da una solución ni se crea algo nuevo.

\begin{tabular}{llll}
\cline { 2 - 3 } & \multicolumn{2}{c}{ Las discusiones y contro- } & \\
versias que se establecen & & \\
separan y alejan a las & & \\
personas, posibilitando la & Contexto de & Pautas de \\
Confrontación & $\begin{array}{l}\text { inmersión en otros } \\
\text { entornos sociales. }\end{array}$ & los significa- & interacción \\
& & dos & y conflictos
\end{tabular}

Dinámica familiar de agresividad y violencia.

Agresividad, violencia, maltrato, irrespeto, indelicadeza con las cosas de la casa, hurto, como patrones de interacción.

Este método permitió la comparación y contrastación — por semejanzas y diferencias-de las categorías y subcategorías creadas en la investigación. De la agrupación de 
fragmentos, subcategorías e indicadores emergieron once categorías: 1) pautas de interacción familiar; 2) alteración de las emociones y expresiones sobre la agudización del conflicto; 3) significados de la dinámica familiar asociados al consumo; 4) rol del padre y rol de la madre en la dinámica del conflicto familiar; 5) aspectos simbólicos y actores asociados al consumo sustancias psicoactivas; 6) factores simbólicos emergentes en el comportamiento social; 7) proceso de transformación de significados; 8) símbolos en contextos relacionales; 9) transformación de significados y símbolos en el proceso de comunicación; 10) construcción de contextos transformadores de significados y símbolos; y 11) transformación de significados y símbolos como proceso de aprendizaje. De estas categorías, para la construcción del presente artículo fue posible enriquecer el contenido interpretativo sobre: a) pautas de interacción familiar; b) alteración de las emociones y expresiones; c) roles del padre y de la madre.

\section{Resultados}

La información registrada en torno a la pregunta ¿qué significados y contextos relacionales construyen padres, madres y adolescentes ante el consumo de sustancias psicoactivas?, permitió dar cuenta de tres componentes centrales: los significados en contexto que visibilizaron pautas de interacción familiar tanto en los conflictos familiares como de cambios en las relaciones; entre estas mediaron estrategias basadas especialmente en confrontaciones y en acciones-reacciones, donde la tendencia fue el enfrentamiento y el quiebre de las relaciones entre los integrantes de las familias. Segundo, la alteración de las emociones y expresiones de la agudización del conflicto, asociada a las pautas relacionales confrontativas que agudizaban el desequilibrio emocional del grupo familiar. Y, tercero, la construcción de significados sobre el rol del padre y rol de la madre en quienes se diluye el manejo de la autoridad, justificado en la ausencia de la figura paterna paralela al desconocimiento de la figura materna.

\section{Significados sobre los conflictos: contextos y pautas} de interacción familiar

Las pautas de interacción implicaron aquellas acciones e interacciones repetitivas que entorpecieron el bienestar de las personas y sus contextos relacionales sociofamiliares. Cuando las pautas relacionales llevaron consigo situaciones problemáticas, cada persona buscó, inicialmente, una manera de salir de ellas, tales como el diálogo o acercamientos 
mediante reclamos y preguntas sobre lo que podría estar sucediendo en la persona. No obstante, a medida que pasaba el tiempo y los intentos de solución, la pauta relacional se agudizó y se incrementaron las dificultades, a la vez que se unieron problemas adicionales.

Las pautas identificadas reflejaron: a) la complejidad de los vínculos co-construidos por los integrantes de las familias durante el proceso de consumo; b) la condición y rol de cada uno; c) las diversas formas de interacción; y d) el surgimiento de pautas interactivas que agudizaron acciones violentas. El conocimiento sobre el consumo de sustancias psicoactivas cambió el contexto relacional y afloraron otros problemas a nivel paternomaterno filial de enfrentamiento y golpes, mientras que a nivel conyugal hubo separaciones y abandono del hogar por parte del padre. Las familias que habían tenido una relación aparentemente tranquila comenzaron a percibir un contexto relacional hostil y polémico; aumentaron las controversias dolorosas, dañinas y desesperanzadoras como pauta de convivencia, expresadas en separaciones, alejamientos, gritos, insultos y golpes. Un contexto relacional que se convirtió en justificación para la salida del hogar, especialmente del padre-esposo o del hijo que consumía sustancias psicoactivas. Unido a este contexto familiar, los hijos consumidores agudizaron su inmersión en entornos sociales externos al grupo familiar, donde predominaban ambientes de riesgo:

Todo son discusiones y alegatos. Entonces, tal vez, por eso uno evade las situaciones, se retira. Yo no permanecía en mi casa porque todo era discusiones, alegatos. ¡Qué pereza uno llegar a lo mismo!, porque al llegar a la casa todo empezaba, si ve. Entonces prefería no llegaba a mi casa. Los golpes, insultos, las malas palabras. Nosotros no éramos una familia en la que se escuchaba un hijueputazo. Desde ahí empezaron los golpes, los disgustos, el hurto entre nosotros mismos; yo irrespetaba los espacios de mi mamá y me le llevaba las cosas». (Adolescente, 18 años)

En estos contextos, caracterizados por el maltrato, el irrespeto, la predisposición o indisposición, la distorsión de los mensajes, las tensiones, las sensaciones de malestar, la incomodidad, la inconformidad, el estrés, la controversia y el hurto, se manejaron en medio de acciones como: censura, señalamiento, reclamo, justificación, engaño, encubrimiento, confrontación, rechazo, falta de aceptación, rivalidad, distanciamiento, abandono, entre otras. La repetición de esta forma comunicativa creó patrones de interacción que atormentaron a las personas involucradas. Fueron pautas relacionales donde se explicitaban contrastaciones sociolingüísticas, tales como: 
Esto era una destrucción de todo, del diálogo, afecto, respeto. Ya al entrar a la casa nadie saludaba a nadie; solamente comíamos y nos acostábamos. Prácticamente en la convivencia todo no era igual; algunos miembros de la familia ya no les hablaban a otros. Todo se va destruyendo poco a poco. (Adolescente, 17 años)

[Debido al hurto de dinero]. Yo fui y se los busqué, se los encontré, se los entregué y le di una pela muy fuerte a mi hijo, y en esa pela que le di, le zafé el hombro. (Madre, 56 años)

Uno llegaba a la casa y ya no podía ni dialogar. Llegaba a hacer lo mismo; siempre era el malo del paseo y me alegaban. La manera en que hacía sufrir a las personas por el estado en el que estaba, pero ellos se desquitaban y desahogaban conmigo... Todo se volvía peor. (Adolescente, 18 años)

En varios momentos, las familias llegaron a retaliaciones o escaladas simétricas que dejaron huellas en el cuerpo de cada persona. Según Sánchez-Jiménez (2014), el intercambio de las voces engendra tensiones personales y sociales de la vida cotidiana. Las personas co-construyen diálogos confrontativos permanentes y, en medio de ellos, afloran exaltaciones emocionales que hacen daño a las relaciones, a las interacciones y a los vínculos sociofamiliares.

\section{Alteración de las emociones y expresiones de la agudización del conflicto}

Sobre los estados alterados de las emociones que incidieron en el juicio o la conducta de cada persona, cuando se crearon las formas interactivas planteadas hasta aquí, las personas comenzaron a vivir diversas formas de alteración en los estados emocionales:

Yo a veces lloro mucho, me da mucha tristeza. NN cada ratico me ve así y procuro que no lo haga y me dice: —mami, ¿qué tiene?. Le respondo que nada, pero él contesta: —mami usted está llorando, ¿qué le pasa? Y yo le digo, no amor, estoy aburrida. (Madre, 56 años)

La confrontación entre padres, madres e hijos crearon, según ellos, sentimientos de «frustración, insatisfacción» y emociones de «ira, miedo, ansiedad, culpa, pereza y soberbia», especialmente. Los contextos de confrontación constituían, en esos momentos, una plataforma adecuada para la generación y perpetuación de relaciones agresivas y violentas que, relacionadas con el consumo de sustancias psicoactivas, hacían más complejo el problema. Era una especie de círculo vicioso: 
Porque yo sé que él tuvo la culpa en muchos aspectos por dejarse influenciar, cierto, pero yo también soy altamente culpable de las actitudes de él, yo lo reconozco (...). De verdad me siento muy culpable y por eso no le estoy descargando la responsabilidad a él, no le estoy echando la responsabilidad (...). Yo sentía muchas emociones encontradas y yo sentía culpa, rabia, dolor, decepción; una infinidad de cosas. (Padre, 48 años)

Porque al usted escuchar una palabra como ¡uy, que malparido usted!, vea una cosa de esta y lo otro, vicioso; que le diga a uno vicioso la mamá es feo y el daño moral lo deprime a uno; esa palabra, saber que usted es un consumidor. Pero que le digan vicioso duele. (Adolescente, 18 años)

Casi siempre cuando nos enfrentamos a un conflicto no encontramos solución y si uno ha consumido no encuentra alternativas porque se está bajo efectos de algo, que para uno supuestamente no hace nada, mientras que la familia piensa diferente. (Adolescente, 17 años)

En estos casos, las emociones se entrelazaron con formas de reacción de las personas e inciden en acción co-construida relacionalmente con la familia. Por ello, cuando la emoción era de ira, rabia, decepción, las reacciones más frecuentes fueron de huida o confrontación negativa que terminaban en relaciones violentas. Estas situaciones alejaban las posibilidades de un encuentro favorable para la mediación y solución de las mismas y dificultaba llegar a coordinaciones comunicativas de resolución de conflictos entre las personas, grupos familiares o sociales involucrados. La reacción y el acontecimiento favorecieron la manifestación y prolongación de las dificultades e instauraron nuevas pautas de interacción violenta que se extendían en el tiempo.

\section{Roles del padre y la madre en medio del conflicto familiar}

Los roles que ostentó cada uno de los integrantes de la familia asociados a los significados construidos, respondían a una tradición sociocultural patriarcal donde los padres se ven como figuras de autoridad, mientras las madres son débiles para asumir este rol, lo cual incidía en las dinámicas e interacciones familiares. Es el caso de la forma como los adolescentes de esta investigación veían la autoridad delegada al padre y, cuando éste se iba de la casa, la madre no alcanzaba a ser reconocida como figura de autoridad. Por el contrario, las acciones de ella eran minimizadas, al punto que lo que decía o hacía con su familia perdía valor y sus palabras no eran escuchadas. En estas condiciones, la madre quedaba despojada de autoridad, vulnerada en sus derechos y deberes, situa- 
ción que era aprovechada por los adolescentes. Ellos expresaron perder el control sobre sus impulsos y demandaron tener en casa al padre, ya que la presencia solo de la madre no les era suficiente. En este contexto relacional la madre queda vulnerada y expuesta a ser agredida permanentemente.

$\mathrm{Al}$ principio la figura de autoridad que uno ve en la casa se va, se retira, quedando la figura que es más flexible a todo; entonces, al ver que solo queda la figura más flexible uno se vuelve más agresivo; eso, básicamente eso. (Adolescente, 18 años)

Yo pensaría que por falta de esa persona que esté ahí, con ese apoyo de palabras, de empuje, motivación; o en mi caso fue eso, porque yo me sentía solo; no había nadie que estuviera ahí. A pesar de que tenía mi mamá, pero no. (Adolescente, 17 años).

La ausencia de la figura paterna significó falta de poder y autoridad en el contexto familiar, mientras la madre permaneció en una condición de desprotección, debilidad y falta de apoyo. La mujer en estos contextos dejó de ser una figura representativa de poder y autoridad para los adolescentes y, a pesar de estar en casa, su presencia no era considerada como significativa. Paralelo a ello, pese a que las madres reconocieron el papel de la autoridad del padre, también negaron que su presencia en la casa fuera la fuerza que evitara el consumo de sustancias psicoactivas del hijo adolescente:

Hubo ausencia de la figura paterna, porque en ese tiempo yo vivía sola con él. (Madre, ${ }_{5}^{6}$ años)

En ese momento había mucha soledad, porque los muchachos no estaban; el papá nunca estuvo y, aunque estuviera, no ayudaría de a mucho. (Madre, 50 años)

Unido a estos problemas relacionales, la madre cabeza de hogar debía realizar otras labores para sostener el hogar y no podía estar al lado de su hijo; mientras que el padre desaparecía, al tiempo que era ausente en todo apoyo emocional, afectivo, educativo o económico. Frente a los padres, en las entrevistas no se encontró censura como sí ocurrió con la madre. El poder e impacto que tiene la ausencia del padre como figura de autoridad llega a tal punto que a la madre, a pesar de estar ahí enfrentándose al conflicto, le restan reconocimiento y ella se siente y se asume como ausente y aprende a minimizar su capacidad de autoridad: 
Primero la ausencia del papa y la mía en cierta forma en hogar, porque yo estaba todo el día trabajando, llegaba dos o tres de la tarde y el muchachito no estaba, ya estaba libre. Entonces la ausencia del papá, sí, la ausencia de las personas que estaban a cargo de él. (Madre, 50 años)

Yo a veces pienso, profe, que como siempre he trabajado tanto, de pronto el sentirse tan solo. Vivíamos bien con mi esposo y mis hijos, pero como yo trabajaba de lunes a sábado a veces los domingos, el papá trabajaba de lunes a viernes; él se iba a trabajar un sábado para la finca y los dejaba solos, nunca compartía con ellos. (Madre, 45 años)

La madre experimentaba un estado de vacío y era invalidada por la angustia, a partir de la experiencia de abandono y conflicto, convirtiéndose en una especie de «gladiadora». Cuando sentía que le faltaban las fuerzas, sacaba lo que ellas llaman «su último aliento», no para recuperar la autoridad, sino para asumir el reto de perseverar en la superación del conflicto.

Yo dije, me tocó y si me tocó y hay que sacarlo adelante. (Madre, 56 años)

Yo creí sinceramente que me iba a morir; para mí fue muy duro. Él era el niño, ejemplo en la casa (...) que tire a mi hijo a la calle le voy a demostrar a usted que a ese niñito lo voy a sacar adelante; yo no sé cómo voy hacer, pero que lo saco, lo saco. (Madre, 50 años)

Yo le discutía al papá, le decía que nunca lo iba a dejar con el problema, que iba a luchar con él hasta lo último, hasta que se dejara ayudar. (Madre, 45 años)

El rol del padre y la madre, en medio de la dinámica del conflicto familiar, estuvo enmarcado por las creencias y tradiciones culturales que actuaron como patrones inamovibles dentro de los grupos familiares, dejando de lado otros aspectos que intervinieron en las relaciones familiares que posibilitaron el afrontamiento y la transformación de conflictos.

\section{Discusión}

Con respecto a la pregunta sobre ¿qué significados y contextos relacionales construyen padres, madres y adolescentes ante el consumo de sustancias psicoactivas?, se logra develar aspectos sobre la dinámica relacional en la creación y comprensión de con- 
textos y significados asociados a los conflictos familiares y los cambios que surgen a medida que avanza el problema o emergen modificaciones en las relaciones. Las pautas relacionales problemáticas están más asociados a las crisis e inducen a la búsqueda de soluciones y construcción de estrategias de cambios que agudizan el problema. Con el tiempo, la pauta relacional problemática en medio de los vínculos familiares incrementan las dificultades creadas y atraen otros problemas adicionales que, en algunos momentos, son colaterales y luego pasan a ser centrales y viceversa. «Esto significa que la crisis es a la vez reveladora de aquello que permanece oculto en las épocas ordinarias y efectora de procesos de transformación» (Hernández, 2004, p. 101).

El conocimiento sobre el consumo de sustancias psicoactivas en un integrante de la familia cambia el contexto y las pautas relacionales. Afloran plataformas interactivas propicias para el mantenimiento de este problema como para el origen de otros conflictos. La familia que ha tenido una relación aparentemente tranquila, comienza a percibir un contexto relacional hostil y polémico. Las confusiones emocionales, afectivas, sociales y psicológicas en cada una de las personas salen a la luz y, mientras tanto, las estrategias para la solución terminan siendo igualmente confusas. Las situaciones adversas priman y generan otras situaciones que agudizan el problema. En la dinámica familiar aumentan las controversias dolorosas, dañinas y desesperanzadoras como pautas de convivencia, lo cual puede expresarse en separaciones, alejamientos, gritos, insultos y golpes que configuran patrones de interacción violentos. Un contexto relacional complejo que facilita la ausencia de los integrantes de la familia y su inmersión en otros entornos sociales externos al grupo familiar, donde predominan ambientes de riesgo a la integridad de quien se aleja de su casa.

En este contexto relacional, los significados sobre las dinámicas familiares y las situaciones problemáticas construidas por los adolescentes del estudio tienen como eje central la hostilidad. Ellos dan cuenta de interpretaciones que muestran un entorno familiar destructivo, con permanente discusión, maltrato emocional, verbal y físico, así como con resistencia para aceptar o negociar normas de interacción familiar. Esta dinámica se convierte en un factor permisivo para que el adolescente permanezca la mayor parte del tiempo lejos del entorno familiar y para que incremente el consumo. Una de las razones que prima en las respuestas es que él lo hace para desconectarse de la realidad y poder enfrentar el ambiente agresivo, violento y resistir la confrontación a la hora de regresar. Las confusiones emocionales, afectivas, sociales y psicológicas en cada una de las personas salen a la luz y, mientras tanto, los mecanismos o estrategias para la solución son 
también confusos. Es decir, los sentimientos de frustración, insatisfacción y emociones de ira, miedo, ansiedad, culpa, pereza y soberbia, se enfrentan a los sentimientos de amor y protección que pudieran sentir de su padre y madre. Al primero lo perciben lejano y ausente y, a la segunda, amorosa en algunos momentos, aunque en otro violenta y débil.

Los padres y las madres interpretan el contexto de manera diferente. Su lectura está focalizada en corregir y mantener el poder y la autoridad en casa. Consideran que las actitudes frente a los hijos adolescentes les sirve para ejercer control, ayudar, orientar, cuidar, corregir, enseñar y apoyar. Ellos reconocen que la violencia se usa como estrategia de corrección o manejo del cual se desprenden daños físicos y emocionales sin mejores resultados. Unido a esto, para las madres del estudio es importante delegar la autoridad, el control y manejo de la dinámica familiar en el padre, ya que su lugar como mujer y figura de autoridad es débil.

Ante el consumo de sustancias psicoactivas, el desconocimiento de la madre como figura de poder y autoridad es un factor de riesgo para el manejo y afrontamiento de esta problemática, asociado al sistema cultural patriarcal como engranaje de creencias que discriminan a la madre y la ubican en un segundo plano respecto al padre.

En el marco de contextos relacionales traspasados por el consumo de sustancias psicoactivas, no siempre este problema emerge de algo que está confuso en las familias o sus relaciones familiares. También el consumo puede emerger por situaciones colaterales y externas al ámbito familiar, lo cual no deja de lado la importancia que tiene la familia del manejo y abordaje del mismo.

No obstante, los artículos científicos y tesis de maestría de los últimos cuatro años (que hacen énfasis en la familia) resaltan como causas del consumo las formas relacionales alteradas, las dificultades en la educación, socialización y comunicación, especialmente paterno-materno filiales; estos son escenarios protagónicos para la instauración del consumo de sustancias psicoactivas en los adolescentes y jóvenes. La falta de afecto, de claridad en las normas, en la comunicación, disciplina inconsistente, excesivo castigo y el manejo de la autoridad se convierten en riesgo (Feito-Crespo, 2016; Prieto-Montoya et al., 2016; Quimis \& Plúa, 2019; Espinosa et al., 2016). Esto se agrava cuando hay dificultades en los procesos de comprensión y acompañamiento, unidos, por un lado, a factores personales asociados a alteraciones en la autoestima, la autopercepción, la autoimagen y la confianza en sí mismos y, por el otro, a factores sociales en los que inciden los grupos de pares (Castaño-Castrillón et al., 2017; Choéz et al., 2017; Forero et al., 2017; Noreña, 2017; Peláez, 2018). Otros autores destacan los cambios en los roles de género (Páez-Mar- 
tínez, 2016), el divorcio o separación de los padres y la convivencia de los hijos con otros familiares (Aguirre-Guiza et al., 2017). Otro elemento de riesgo es la presencia de vínculos débiles asociados a la ausencia de la figura paterna, su autoridad y función protectora (Noreña, 2017).

En cuanto a los vínculos afectivos, uno de los riesgos es la disminución o poca expresión de ellos por parte de los padres hacia los hijos (Apolo et al., 2018; Noreña, 2017). Para Alonso-Castillo et al. (2017) la transformación de los vínculos afectivos en la adolescencia genera fracturas en las relaciones familiares y comportamientos agresivos. Esto último es una de las razones por las que los adolescentes sienten insatisfacción y culpabilizan a la madre, al padre o a la familia en general de su situación. Nuevos estudios están mostrando que otros factores de riesgo asociados al consumo de sustancias psicoactivas son las prácticas de violencia filioparental ejercida por hijos e hijas adolescentes (ÁvilaNavarrete et al., 2019) y la influencia de los integrantes de la familia quienes invitan o permiten que desde temprana edad los niños y adolescentes consuman sustancias como alcohol y otras drogas (Martínez et al., 2019).

Miradas como estas tientan a algunos investigadores a buscar variables o categorías que permiten demostrar que el consumo de sustancias psicoactivas está directamente relacionado con una forma de disfunción familiar, como lo señalan Alonso-Castillo et al. (2017), Páez-Martínez (2016) y Espinosa et al. (2016).

Si la mirada está en el consumo como foco de problemas familiares, pese a que se nombren otras variables ambientales y sociales, la lectura hegemónica que culpabiliza a la familia de este problema social predominará bajo una lupa normativa de las relaciones sociofamiliares. De ahí que no es fácil encontrar preguntas investigativas que centren su atención académica en los cambios de las familias y sus relaciones cuando un integrante de ella inicia el consumo de sustancias psicoactivas. Cualquiera sea el lugar de donde emerja el consumo, en el momento en que el problema es evidente y se reconoce, las familias no escapan del desconcierto y la pregunta centrada en la falla. Un punto de inicio para el señalamiento a lo que hacen o dejan de hacer los integrantes de las familias es el ámbito en el cual el adolescente deposita con más fuerza el señalamiento y desplaza su responsabilidad en otros. Él no se reconoce como actor y creador de su contexto y como quien optó por el consumo. 


\section{Consideraciones finales}

Como se mencionó en la sección del método, de las diez familias que cumplían con los criterios cualitativos de selección, solo cuatro aceptaron voluntariamente participar como informantes. Estas decisiones se mueven desde dos lugares psicosociales y relacionales. En quienes no participaron, sus explicaciones se centraron en el temor a involucrarse con historias que consideraron negativas, privadas o íntimas, cuya exposición podía detonar culpa y vergüenza, unido al temor de activar enfrentamientos en las relaciones familiares. Y, para las familias de este estudio, las narraciones permitían ver procesos creativos asociados a la capacidad de crecimiento personal y familiar, así como una experiencia digna de admiración, importante como referencia y aprendizaje para otros grupos familiares que viven el problema del consumo de sustancias psicoactivas.

En este contexto y de acuerdo con los significados construidos por dichas cuatro familias, pudo identificarse que el problema del consumo va más allá de que sean diferentes o diversos los discursos y significados que le son dados a los integrantes de las familias. El problema está soportado en el predominio de discursos patriarcales excluyentes que llevan a que las parejas —en relación paterno/materno filial_ construyan formas negociadas de comunicación y socialización con sus hijas e hijos. Los discursos hegemónicos dificultan crear pautas de crianza coordinadas, coherentes y claras, donde primen diálogos generativos personales y grupales con una población adolescente activa que cuestiona y reta poderes, normas y acuerdos sociofamiliares. Incluso, esto aplica para toda forma de organización familiar que va más allá de la familia hegemónica, heterosexual o patriarcal.

Es decir, mientras en las familias no se construyan relacionas democráticas, justas y colaborativas, donde la mujer-madre-esposa se reconozca como interlocutora válida, con poder para tomar decisiones y respetarlas, donde los padres y las madres logren crear coordinaciones sociofamiliares y sociolingüísticas que los unan para afrontar el contexto relacional del consumo de sustancias psicoactivas, este problema seguirá ganando un espacio propicio para la agudización y el surgimiento de nuevos conflictos.

Mientras el problema persista, las normas de convivencia seguirán siendo inconsistentes y fácilmente pasarán de la flexibilidad a la rigidez, hasta llegar al abandono que destruye toda de forma de relación. Las confusiones entre padres, madres y adolescentes agravan la interacción y relaciones sociofamiliares, y el consumo de sustancias psicoactivas termina siendo un detonante de problemas que comienzan a ser evidentes y que se encontraban como telón de fondo. 
La invitación para que haya nuevas pautas interactivas está lejos de ver la causa en el padre ausente, en la falta de autoridad paterna o en los problemas de las parejas, entre otros; pues también existen familias en las que, pese a la existencia de estas situaciones, no llegan a tener el problema de que un hijo o hija consuma sustancias psicoactivas. De seguir así, no se logrará aportar otras conclusiones ni otras miradas generativas que contribuyan a los procesos de abordaje e intervención de las relaciones familiares en contextos de consumo.

Por uno u otro lado, siempre habrá un interrogante al respecto, debido a la complejidad del mundo social, personal y familiar que construyen los sujetos dentro y fuera del contexto familiar. «Los cambios en la familia son evidentes mediante la emergencia de situaciones colaterales caracterizadas por comportamientos y relaciones que estaban como telón de fondo» (Sánchez-Jiménez, 2017, p. 1184). Lo que, en otras palabras, es reconocido desde la perspectiva sistémica como contextos relacionales multiproblemáticos, en los cuales el inicio del consumo puede estar sostenido por factores ajenos a las relaciones familiares, pero que luego entran a ser parte de ellas. Desde la terapia familiar, estos casos son «un importante foco de intervención a considerar, siendo necesario diferenciar entre la estructura familiar y los procesos relacionales que implica la cotidianeidad a la que están expuestos los miembros de cada familia» (Saban-Ayala \& Alarcón-Espinosa, 2018, p. 938).

Por lo tanto, sin desconocer el cuidado que necesita toda familia, no puede generalizarse que los problemas en sus relaciones son detonantes del consumo y terminar en una posición tradicional de culpar a la familia de un problema que es producto de factores multidimensionales y que hoy es un asunto de salud pública. La invitación desde este estudio es a profundizar, por un lado, en las conexiones sociolingüísticas y patrones relacionales que, desde las personas consumidoras en contextos sociofamiliares, organizan la agudización del consumo, al igual que el lugar de la familia para impulsar conexiones detonantes de cambio.

\section{Agradecimientos}

A la Universidad de Caldas y al grupo de investigación Colectivo estudios de familia (Categoría A) por garantizar profesores de alta calidad académica, quienes desde sus seminarios y la dirección de tesis dieron las bases epistemológicas, teóricas y metodológicas para el trabajo de grado del que se desprende este escrito. También a las profesoras 
evaluadoras Gretel Espinosa Herrera (Doctora en Ciencias Sociales, Niñez y Juventud) y a Liliana Patricia Rivera González (Magíster en Intervención en Relaciones Familiares). Especial agradecimiento a las cuatro familias que fueron el corazón del contenido de la tesis y de este artículo.

\section{Referencias}

Aguirre-Guiza, N. C., Aldana-Pinzón, O. B., \& Bonilla-Ibáñez, C. P. (2017). Factores familiares de riesgo de consumo de sustancias psicoactivas en estudiantes de una institución de educación media técnica de Colombia. Revista de Salud Pública, 19(1), 21-3o. http://dx.doi.org/10.15446/rsap.v19n1.41785

Alonso-Castillo, M., Yañez-Lozano, Á., \& Armendáriz-García, N. A. (2017). Funcionalidad familiar y consumo de alcohol en adolescentes de secundaria. Health and Addictions/Saludy Drogas, 17(1), 87-96. https://doi.org/10.21134/haaj.v17i1.286

American Psychological Association. (2010). Principios éticos de los psicólogos y código de conducta APA. Autor.

Apolo, A., Murillo, D. A., \& Valarezo, M. L. (2018). Aspectos conativos y estadios para el cambio en adolescentes consumidores de drogas [Tesis de pregrado, Universidad Técnica de Machala]. Repositorio digital de la UTMACH. http:// repositorio.utmachala.edu.ec/handle/4800o/12448

Arcila, P. A., Mendoza, Y. L., Jaramillo, J. M., \& Cañón, O. E. (2010). Comprensión del significado desde Vygotsky, Bruner y Gergen. Diversitas: Perspectivas en Psicología, 6(1), 37-49.

Ávila-Navarrete, V. C. (2017). ¿Corresponsabilidad familiar en instituciones de reeducación para adolescentes infractores? Revista Latinoamericana de Ciencias Sociales, Niñez y Juventud, 15(2). https://doi.org/10.11600/1692715x.1522712102016

Ávila-Navarrete, V. C., León-Catachunga, Y., \& Gutiérrez-Tamayo, C. A. (2019). Relación entre el consumo de sustancias psicoactivas y la violencia filioparental en adolescentes. Drugs and Addictive Behavior, 4(2), 290-303.

Castaño-Castrillón, J. J., García, S., Luna, J., Morán, M., Ocampo, D., \& Ortiz, L. (2017). Estudio de factores asociados y prevalencia de consumo de sustancias psicoactivas ilegales en estudiantes de una universidad colombiana. Revista de la Facultad de Medicina, 65(1), 23-30. https://doi.org/10.15446/revfacmed.v65n1.56471 
Choéz, M. M., Figueroa, M. S., \& Alava, C. J. (2017). Factores de riesgo para la adicción en los adolescentes. Sinapsis, 2(11). 1-15. https://doi.org/10.37117/s.v2i11.126

Domínguez, Y. G. \& Figueroa, P. A. (2019). Sustancias psicoactivas y los trastornos de conducta en adolescentes [Tesis de pregrado, Universidad Estatal del Sur de Manabí]. Repostorio digital UNESUM. http://repositorio.unesum.edu.ec/handle/5300o/1655

Feito-Crespo, L. (2016). El papel de la familia en el consumo de sustancias de adolescentes y jóvenes españoles. Universidad Pontificia Comillas.

Forero, I., Siabato, E., \& Salamanca, Y. (2017). Ideación suicida, funcionalidad familiar y consumo de alcohol en adolescentes de Colombia. Revista Latinoamericana de Ciencias Sociales, Niñez y Juventud, 15(1), 431-442. http://dx.doi.org/ $10.11600 / 1692715 \times .1512729042016$

Gergen, K. J. (1996). Realidades y Relaciones: aproximaciones a la construcción social. Paidós. Gergen. K. J. (2007). Construccionismo social: aportes para el debate y la práctica. Ediciones Uniandes.

Hernández, A. (2004). Psicoterapia sistémica breve: la construcción del cambio con individuos, parejas y familias. El Búho.

Martínez, E., Scoppetta, O., \& Martín A. (2019). Permisividad parental y diferencias de género en el consumo de alcohol en escolares. Drugs and Addictive Behavior, 4(2), 214-224.

Martínez, J. (2015). Funcionamiento familiar y apoyo social en el consumo de drogas y las conductas delictivas de los adolescentes. [Tesis doctoral, Universidad de Málaga]. RiUMA. http://hdl.handle.net/10630/10089

Muñoz, J. \& Sahagún, M. (2017). Hacer análisis cualitativo con Atlas.ti 7: manual de uso. https://manualatlas.psicologiasocial.eu/atlasti7.pdf

Noreña, S. P. (2017). Dinámicas relacionales en familias con un miembro consumidor de sustancias psicoactivas [Tesis de Maestría, Pontificia Universidad Javeriana, Cali]. http://vitela.javerianacali.edu.co

Páez-Martínez, R. M. (2016). ¿Des-víos de la familia en la formación de los hijos e hijas? Nuevos perfiles, funciones constantes. Revista Latinoamericana de Ciencias Sociales, Niñez y Juventud, 14(1), 261-272. https://doi.org/10.1160o/1692715x.14117260215

Peláez, O. L. (2018). Relación entre pautas de crianza y el consumo de sustancias psicoactivas en adolescentes. http://repositorio.ucp.edu.co:8080/jspui

Prieto-Montoya, J. A., Cardona-Castañeda, L. M., \& Vélez-Álvarez, C. (2016). Estilos parentales y consumo de sustancias psicoactivas en estudiantes de $8^{\circ}$ a $10^{\circ}$. Revista 
Latinoamericana de Ciencias Sociales, Niñez y Juventud, 14(2), 1345-1356. https://doi.org/ 10.11600/1692715X.14231161015

Quimis, P., \& Plúa, D. (2019). La familia y las sustancias psicoactivas. [Tesis de pregrado, Universidad Estatal del Sur de Manabí]. Repostorio digital UNESUM. http://repositorio.unesum.edu.ec/handle/53000/1655

Saban-Ayala, K., \& Alarcón-Espinoza, M. (2018). Significados del actuar delictivo adolescente: perspectiva de sus madres. Revista Latinoamericana de Ciencias Sociales, Niñez y Juventud, 16(2), 929-942. https://doi.org/10.11600/1692715x.16219

Sánchez-Jiménez, M. H. (2014). Movimientos conversacionales terapéuticos del problema al cambio y creaciones sociolingüísticas. Revista Latinoamericana de Estudios de Familia, 6, 191-210.

Sánchez-Jiménez, M. H. (2017). Prácticas dialógicas y códigos sociolingüísticos: crisis y cambios familiares en contextos dialógicos. Revista Latinoamericana de Ciencias Sociales, Niñez y Juventud, 15(2), 1179-119o. https://doi.org/ 10.11600/1692715x.1522929072016

Espinosa, K., Hernández, M., Cassiani, C. A., Cubides, Á. M., \& Martínez, M. (2016). Factores relacionados con el consumo de sustancias psicoactivas en una institución educativa de Jamundí Valle, Colombia. Revista Colombiana de Psiquiatría, 45(1), 2-7. https://doi.org/10.1016/j.rcp.2015.06.001

Stanton, M. D., \& Todd, T. C. (2018). Terapia familiar del abuso y adicción a las drogas. Gedisa.

Strauss, A., \& Corbin, J. (2002). Bases de la investigación cualitativa: técnicas y procedimientos para desarrollar la teoría fundamentada. Editorial Universidad de Antioquia.

Universidad de Caldas. (2016). Resolución número 00797. Por medio de la cual se crea y regula el Comité Central de Ética en investigación y los Comités de Ética de las Facultades. Universidad de Caldas.

Valverde, S. (2003). Paul Ricoeur: hermenéutica y simbolismo. Revista Filosofía. Universidad de Costa Rica, 41(104), 51-59.

Vasilachis, I. (2006). La investigación cualitativa. En I. Vasilachis (Coord.), Estrategias de investigación cualitativa (pp. 23-59). Paidós.

Wittgenstein, L. (1953/2008). Investigaciones filosóficas, I y II. Crítica. 